Pacific Journal of Mathematic 


\title{
TWO THEOREMS ON TOPOLOGICAL LATTICES
}

\author{
Alexander Doniphan Wallace
}

A topological lattice is a pair of continuous functions

$$
\wedge: L \times L \rightarrow L, \quad \wedge: L \times L \rightarrow L
$$

( $L$ a Hausdorff space) satisfying the usual conditions for lattice operations. A set $A$ is convex if $x, y \in A$ and $x \leqq a \leqq y$ implies $a \in A$. This is equivalent to $A=(A \wedge L) \cap(A \vee L)$.

After proving a separation theorem involving a convex set we show that a compact connected topological lattice is a cyclic chain in the sense of G. T. Whyburn and that each cyclic element is a convex sublattice. In doing so we rely on some results recently obtained by $\mathrm{L}$. W. Anderson.

THEOREM 1. Let $L$ be a connected topological lattice and let $A$ be a convex set such that $L \backslash A$ is not connected. Then $L \backslash A$ is the union of the connected separated sets $(A \wedge L) \backslash A$ and $(A \vee L) \backslash A$ which are open (closed) if $A$ is closed (open). If $L$ is also compact then $A$ is connected if it is either open or closed.

Proof. Let $L \backslash A=U \cup V$ with $U^{*} \cap V=\phi=U \cap V^{*}$ and let $p \in U$, $q \in V$. The connected set $(p \wedge L) \cup(q \wedge L)$ meets both $U$ and $V$; hence it meets $A$. Adjust the notation so that $(q \wedge L) \cap A \neq \phi$ and thus $q \in A \vee L$. If $(q \vee L) \cap A \neq \phi$ then $q \in A \wedge L$ and hence $q \in(A \wedge L)$ $\cap(A \vee L)=A$. This being impossible we infer that $(q \vee L) \cap A=\phi$ and $q \in(A \vee L) \backslash A=(A \vee L) \backslash(A \wedge L)$. The connected set $(p \vee L) \cup$ $(q \vee L)$ intersects $U$ and $V$ and so intersects $A$. But $(q \vee L) \cap A=\phi$ so that $(p \vee L) \cap A \neq \phi$ and hence $p \in A \wedge L$. Were $(p \wedge L) \cap A \neq \phi$ we would also have $p \in A \vee L$ and so $p \in A$, a contradiction. Thus $(p \wedge L) \cap A=\phi$ and $p \in(A \bigvee L) \backslash A=(A \bigvee L) \backslash(A \wedge L)$. Now take $y \in V$ and suppose that $y$ is not in $A \vee L$ so that $(y \wedge L) \cap A=\phi$; then $(p \wedge L)$ $\cap A \neq \phi$ since $(p \wedge L) \cup(y \wedge L)$ is a connected set meeting $U$ and $V$. But this is contrary to the proven fact that $(p \wedge L) \cap A=\phi$. We conclude that $V \subset(A \vee L) \backslash A$ and, dually, that $U \subset(A \wedge L) \backslash A$. It follows that $L=(A \wedge L) \cup(A \bigvee L)$. Now $x \in(A \vee L) \backslash A$ and $x \in L \backslash V$ gives $x \in U \subset(A \wedge L) \backslash A$ and this contradicts the convexity of $A$. Hence $U=(A \wedge L) \backslash A$ and $V=(A \vee L) \backslash A$. To see that $U \wedge L=U$ we need only note that $x \in U$ gives $(x \wedge L) \cap A=\phi$ and thus $(x \wedge L) \cap V=\phi$ (since $x \wedge L$ is connected and contains $x)$ and hence $x \wedge L \subset(A \wedge L) \backslash(A \vee L)=U$.

Received August 6, 1956. This work was supported by the National Science Foundation. 
Dually, $V \wedge L=V$ and these equalities imply that $U$ and $V$ are connected. If $A$ is closed (open) then $U$ and $V$ are open (closed). This completes the proof of the first sentence of the conclusion. If $L$ is also compact then $H^{1}(L)=0$ [3] so that (as is well known) $L$ is unicoherent. But $L$ is locally connected, $L=(A \wedge L) \cup(A \vee L)$, and the sets $A \wedge L$ and $A \vee L$ are connected, and open (closed) [1] if $A$ is open (closed). Hence by a known result [2] we see that $A=(A \wedge L) \cap$ $(A \vee L)$ is connected.

We assume that the reader is familiar with the cyclic element theory of locally connected continua as given in [4]. We recall that a locally compact connected topological lattice is locally connected [1].

THeOREM 2. Let $L$ be a compact connected metrizable topological lattice. Then $L$ is a cyclic chain, each cyclic element of which is a convex sublattice. If $L$ is topologically contained in the plane then each true cyclic element of $L$ is 2-cell and $L$ has the fixed-point property.

Proof. Let $C$ be a true cyclic element of $L$, let $x, y \in C$ with $x \leqq y$ and let $p \in L$ such that $x \leqq p \leqq y$. If $T$ is a maximal chain containing $x, p$, and $y$ then $T$ is an arc from 0 to 1 , as is well known [1]. Hence the set $[x, y]=\{t \mid t \in T$ and $x \leqq t \leqq y\}$ is an are from $x$ to $y$ [1]. Since $C$ is an $A$-set [4] we know that $[x, y] \subset C$ and thus $p \in C$. Hence $C$ is convex. Let $D$ be the cyclic chain from 0 to 1 , that is, $D$ is the smallest $A$-set containing 0 and 1 [4]. Then, by definition, $T \subset$ $D$ and if $x \in L \backslash D$ then the maximal chain $T^{\prime}$ containing $0, x, 1$ is an arc from 0 to 1 and thus $T^{\prime} \subset D$, a contradiction. Hence $D=L$ and $L$ is the cyclic chain from 0 to 1 . Let $T_{0}$ be 0,1 and all points which separate 0 and 1 . Then $L$ is the union of $T_{0}$ and all true cyclic elements meeting $T_{0}$ in two points [4]. Suppose that the true cyclic element $C$ meets $T_{0}$ in the cutpoints $p$ and $q$. Note that neither 0 nor 1 is a cutpoint [3]. If $z$ is a cutpoint then, since $\{z\}$ is convex, $L=$ $(z \wedge L) \cup(z \vee L)$ and thus $z$ is comparable with each $x \in L$, by Theorem 1. We may assume that $p<q$. We will show that $C=\{x \mid p \leqq x \leqq q\}$. The convexity of $C$ proves the containment " $\supset$ ". If $x \in C$ and if, say, $x \leqq q$ is false then we have $q<x$. By Theorem $1, L \backslash q=((q \wedge L) \backslash q)$ $\cup((q \vee L) \backslash q)$ is a separation and $C$ meets both members, contrary to the fact that $C$ is a true cyclic element [4] . Dually, $x \leqq p$ cannot be false, proving the containment " $\subset$ " of the desired equality. It follows that $C$ is a convex sublattice. The cases $p=0$ or $q=1$ are treated similarly. The remaining results follow from the fact that $H^{\prime}(L)=0$ [3] so that $L$ is a locally connected continuum [1] which does not cut the plane [4]. 


\section{REFERENCES}

1. L. W. Anderson, Topological lattices, Tulane University dissertation (1956).

2. A. H. Stone, Incidence relations in unicoherent spaces, Trans. Amer. Math. Soc. 65 (1949) 427-447.

3. A. D. Wallace, Cohomology, dimension and mobs, Summa Bras. Math. 3 (1953) 43-54.

4. G. T. Whyburn, Analytic topology, New York, 1942.

The TUlane University of LOUISIANA 



\section{PACIFIC JOURNAL OF MATHEMATICS}

\section{EDITORS}

H. L. ROYDEN

Stanford University

Stanford, California

R. A. Beaumont

University of Washington

Seattle 5, Washington

\section{A. L. Whiteman}

University of Southern California

Los Angeles 7, California

E. G. Straus

University of California

Los Angeles 24, California

\section{ASSOCIATE EDITORS}
E. F. BECKENBACH
C. E. BURGESS
M. HALL
E. HEWITT

\author{
A. HORN \\ V. GANAPATHY IYER \\ R. D. JAMES \\ M. S. KNEBELMAN
}

L. NACHBIN

I. NIVEN

G. SZEKERES

T. G. OSTROM

M. M. SCHIFFER
F. WOLF

K. YOSIDA

\section{SUPPORTING INSTITUTIONS}

\author{
UNIVERSITY OF BRITISH COLUMBIA \\ CALIFORNIA INSTITUTE OF TECHNOLOGY \\ UNIVERSITY OF CALIFORNIA \\ MONTANA STATE UNIVERSITY \\ UNIVERSITY OF NEVADA \\ OREGON STATE COLLEGE \\ UNIVERSITY OF OREGON \\ UNIVERSITY OF SOUTHERN CALIFORNIA
}

\author{
STANFORD UNIVERSITY \\ UNIVERSITY OF UTAH \\ WASHINGTON STATE COLLEGE \\ UNIVERSITY OF WASHINGTON \\ AMERICAN MATHEMATICAL SOCIETY \\ CALIFORNIA RESEARCH CORPORATION \\ HUGHES AIRCRAFT COMPANY \\ THE RAMO-WOOLDRIDGE CORPORATION
}

Mathematical papers intended for publication in the Pacific Journal of Mathematics should be typewritten (double spaced), and the author should keep a complete copy. Manuscripts may be sent to any of the editors. All other communications to the editors should be addressed to the managing editor, E. G. Straus at the University of California, Los Angeles 24, California.

50 reprints per author of each article are furnished free of charge; additional copies may be obtained at cost in multiples of 50 .

The Pacific Journal, of Mathematics is published quarterly, in March, June, September, and December. The price per volume (4 numbers) is $\$ 12.00$; single issues, $\$ 3.50$. Back numbers are available. Special price to individual faculty members of supporting institutions and to individual members of the American Mathematical Society: $\$ 4.00$ per volume; single issues, $\$ 1.25$.

Subscriptions, orders for back numbers, and changes of address should be sent to Pacific Journal of Mathematics, 2120 Oxford Street, Berkeley 4, California.

Printed at Kokusai Bunken Insatsusha (International Academic Printing Co., Ltd.), No. 10, 1-chome, Fujimi-cho, Chiyoda-ku, Tokyo, Japan.

PUBLISHED BY PACIFIC JOURNAL OF MATHEMATICS, A NON-PROFIT CORPORATION

The Supporting Institutions listed above contribute to the cost of publication of this Journal, but they are not owners or publishers and have no responsibility for its content or policies. 


\section{Pacific Journal of Mathematics}

\section{Vol. 7, No. 2 \\ February, 1957}

William F. Donoghue, Jr., The lattice of invariant subspaces of a completely continuous quasi-nilpotent transformation ................... 1031

Michael (Mihály) Fekete and J. L. Walsh, Asymptotic behavior of restricted extremal polynomials and of their zeros.................... 1037

Shaul Foguel, Biorthogonal systems in Banach spaces ............... 1065

David Gale, A theorem on flows in networks ................... 1073

Ioan M. James, On spaces with a multiplication .................. 1083

Richard Vincent Kadison and Isadore Manual Singer, Three test problems in operator theory .................................... 1101

Maurice Kennedy, A convergence theorem for a certain class of Markoff processes........................................ 1107

G. Kurepa, On a new reciprocity, distribution and duality law ........ 1125

Richard Kenneth Lashof, Lie algebras of locally compact groups ........ 1145

Calvin T. Long, Note on normal numbers .................... 1163

M. Mikolás, On certain sums generating the Dedekind sums and their reciprocity laws ..................................... 1167

Barrett O'Neill, Induced homology homomorphisms for set-valued maps......................................... 1179

Mary Ellen Rudin, A topological characterization of sets of real numbers........................................... 1185

M. Schiffer, The Fredholm eigen values of plane domains 1187

F. A. Valentine, A three point convexity property .........

Alexander Doniphan Wallace, The center of a compact lattice is totally

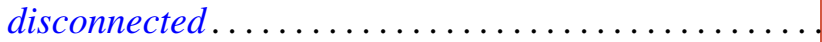

Alexander Doniphan Wallace, Two theorems on topological lattices.

G. T. Whyburn, Dimension and non-density preservation of mappings...

John Hunter Williamson, On the functional representation of certain algebraic systems ... 